\title{
Research on Consumer Satisfaction Model of Electronic Commerce Based on BP Neural Network
}

\author{
Xin Haitao ${ }^{1}$ and Zhang Yanrong ${ }^{2}$ \\ School of Computer and Information Engineering, Harbin University of Commerce, \\ China \\ xinhaitao@hrbcu.edu.cn
}

\begin{abstract}
Starting from classification of satisfaction model, this paper determined the influence of essential factors like product quality, product price, product performance and service quality, distribution efficiency, etc. on consumer satisfaction of electronic commerce by utilizing natural language understanding technology, through the analysis to post purchase evaluation of electronic commerce. And then, an evaluation model for customer satisfaction of electronic commerce enterprises was established on the basis of BP neural network, and implementation, training and verification were carried out to the created network model by utilizing neural network tool box, which verification results showed that this model could obtain relatively accurate evaluation results.
\end{abstract}

Keywords: Neural network, Electronic commerce, BP neural network

\section{Classification of consumer satisfaction and model}

After-purchase process refers to the consumption of goods, after-selection evaluation and processing. As there are many non-measurable factors in consumer expectations, in afterselection evaluation stage, both consumer's satisfaction and dissatisfaction may occur. The data required by this paper studies are all automatically grabbed by the Java program and obtained by parsing the web page. After evaluation data being obtained, method of Natural Language Understanding (NLU) is adopted to analyze consumer's satisfaction degree in electronic commerce, consumer's satisfaction degree is divided into several levels: very satisfactory, satisfactory, generally satisfactory, dissatisfactory, very dissatisfactory. The process is shown in [Figure 1] [1].

Consumer satisfaction is a difference evaluation process occurring after the purchase of product and service, the difference refers to the difference between customer's expectation and perceived performance. The evaluation about whether customer is satisfied or not will affect many other follow-up behaviors of customer [2][3].

The significance of consumer satisfaction is embodied in the following aspects:

(1) Consumer satisfaction may increase more loyal consumers, and the more loyal consumers are, the more they tend to purchase products from the same supplier in the future. Of course, in different industry, the influence of consumer satisfaction on consumer loyalty till repeated purchase is different. The loyal customer is not necessarily satisfied customer, however, there is the tendency for satisfied customer to be changed into loyal customer. In

Article history:

Received (January 16, 2020), Review Result (February 21, 2020), Accepted (March 29, 2020) 
addition to allowing consumer to be satisfied, there are other methods to retain customers, but retaining customers with consumer satisfaction is the most positive method [4].

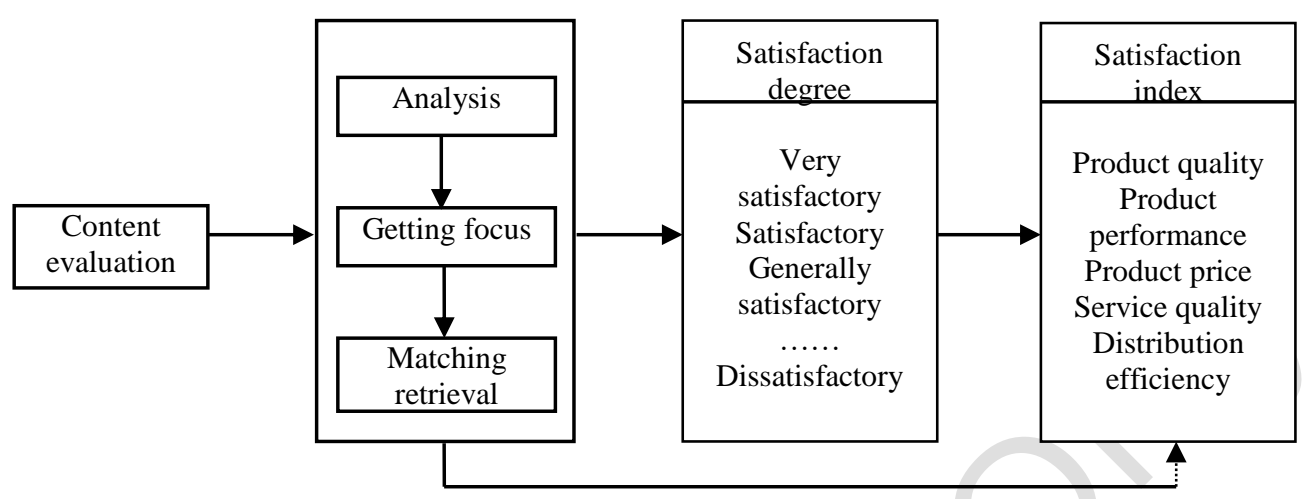

Figure 1. Process of evaluation and analysis

(2) Consumer satisfaction may reduce consumers' sensitivity to price. Satisfied customers usually tend to be willing to pay higher price for benefits they gained, and their tolerance to the rise in price will also be increased. This may be reflected as higher gross profit, increase of gross profit will enable the enterprise to have more resources to improve consumer satisfaction, thus forming a virtuous cycle.

(3) Consumer satisfaction may reduce enterprise's operation cost, which specific performance is: 1 . consumer satisfaction may reduce the future operation cost; 2 . failure cost of the enterprise with high consumer satisfaction is low; 3. for the enterprise with high consumer satisfaction, its cost on attracting new customers is also low.

(4) Consumer satisfaction may increase the overall reputation of the enterprise, thus reducing other costs in operation.

There are three consumer satisfaction models that have been unanimously accepted by scholars, which are expectation- result model and emotion- attribute satisfaction model of Oliver; expectation- perception gap model of Parasuraman, Zeithaml \& Berry; hierarchical satisfaction model of Woodruff, and are described as follows:

(1) Expectation- result model of Oliver

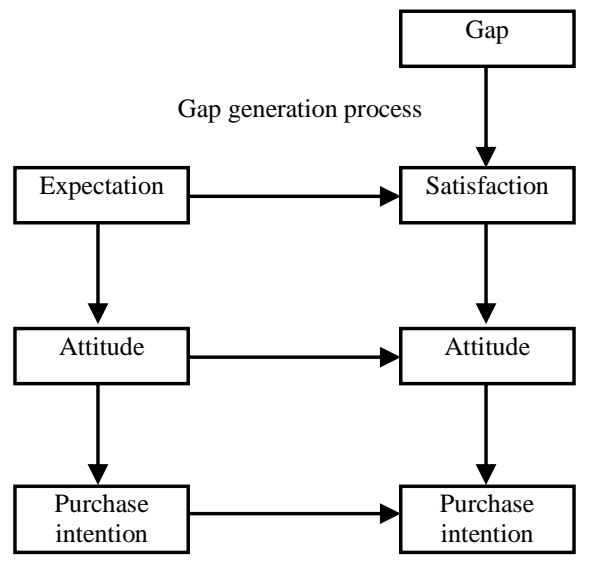

Figure 2. Expectation- result model of Oliver 
As shown in [Figure 2], expectation- result model of Oliver considers that customer satisfaction is divided into four stages: (1) expectation of customer, (2) products or services consumed by customer; (3) generation of gap; (4) generation customer satisfaction.

(2) Emotion- attribute satisfaction model of Oliver

In emotion- attribute satisfaction model of Oliver, positive emotion of customer mainly consists of two respects: interests and likes; negative emotion of customer consists of external factors, internal factors and situational factors. Absolute values of positive emotion and negative emotion determined the degree of customer satisfaction or dissatisfaction.

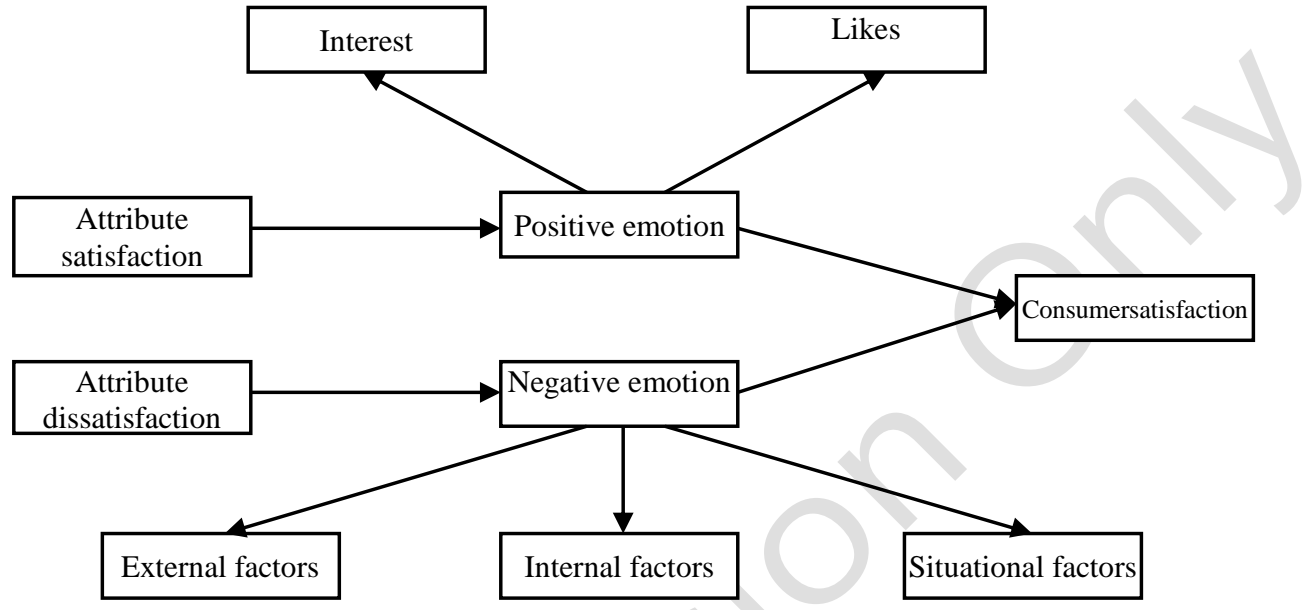

Figure 3. Emotion- attribute model of Oliver

(3) Expectation- perception gap model of Parasuraman, Zeithaml\& Berry

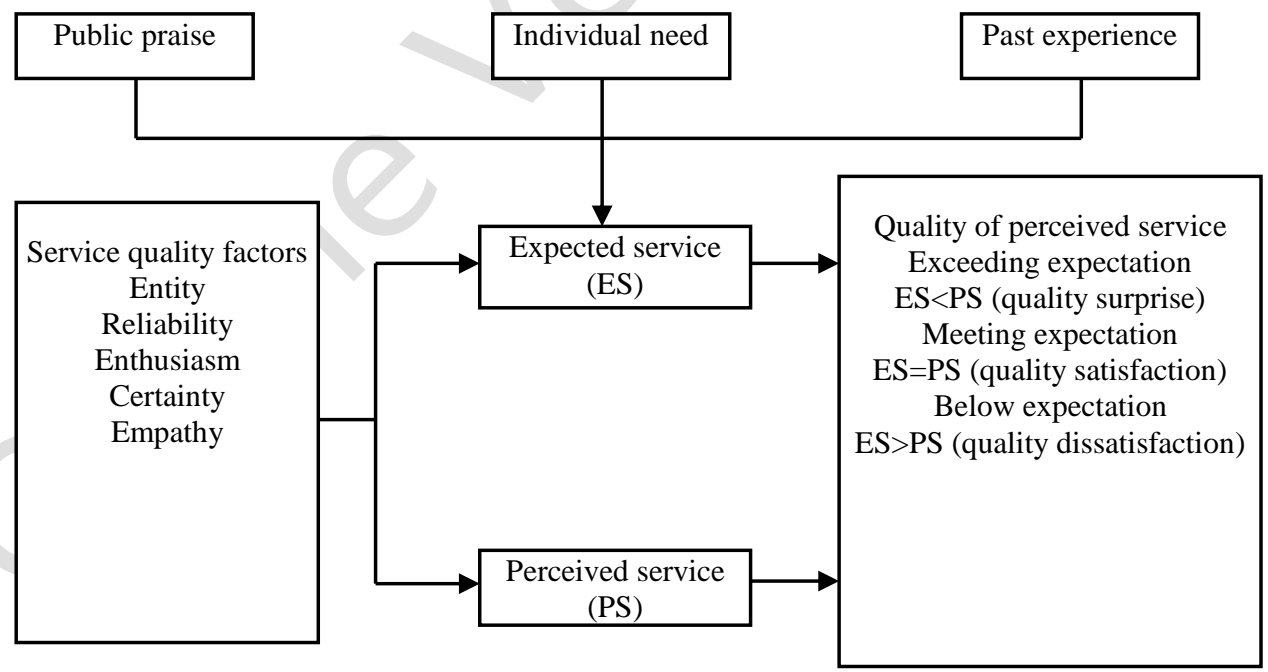

Figure 4. Expectation- perception gap model of Parasuraman, Zeithaml\& Berry

Expectation- perception gap model of Parasuraman, Zeithaml\& Berry is established on the basis of investigation of customer's perception to service quality. Customer's expectation to service is established on the basis of public praise of service, individual need and individual 
past consumption experience. And perception to service quality includes entity, reliability, enthusiasm, certainty and empathy.

(4) Hierarchical satisfaction model of Woodruff

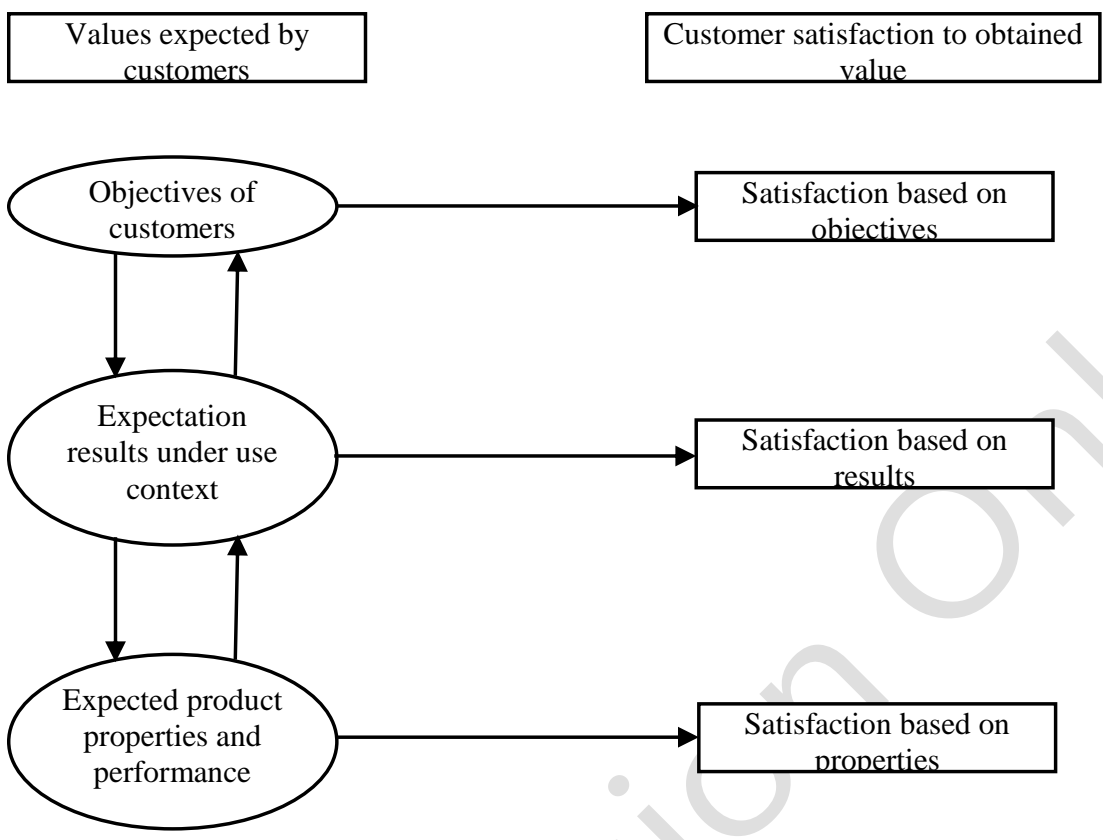

Figure 5. Hierarchical satisfaction model of Woodruff

As shown in [Figure 5], Woodruff thought that satisfaction is hierarchical. On the first layer, if attribute and performance of the product can meet the expectation, then satisfaction based on the attribute will be generated; on the second layer, if the expectation can be met under the use context, then satisfaction based on the results will be generated; finally customers will synthesize the general state after use and generate satisfaction based on the objective on the basis of this. This model combined each stage of consumption, and perfectly interpreted the time problem for generation of customer satisfaction.

Customer satisfaction model of electronic commerce in this paper was obtained on the basis of refinement and improvement to hierarchical satisfaction model of Woodruff, as shown in [Figure 6].

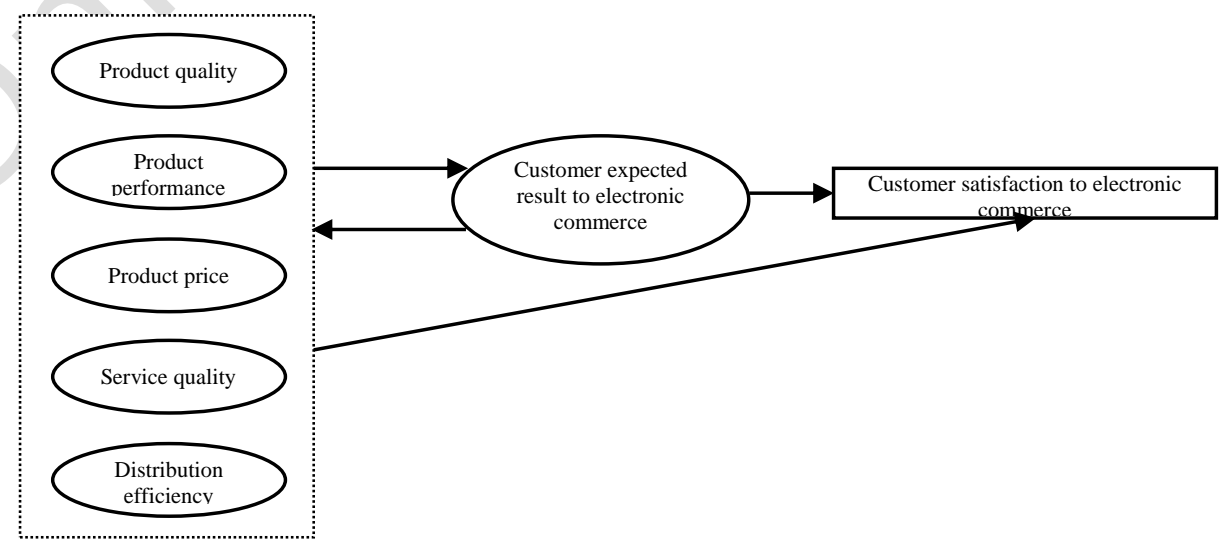

Figure 6. Consumer satisfaction model of electronic commerce 
Through the analysis to the content of post-purchase evaluation of electronic commerce, it is known that the factors like product quality, product performance, product price, service quality, distribution efficiency, etc. and consumer expected results of electronic commerce will interact with each other, and have influence on the customer satisfaction of electronic commerce.

\section{Evaluation of consumer satisfaction}

The existing mainstream evaluation models mainly include Sweden Consumer Satisfaction Index Model (SCSB), American Consumer Satisfaction Index Model (ACSI), and Europe Consumer Satisfaction Index Model (ECSI).

\subsection{Sweden Consumer Satisfaction Index Model (SCSB)}

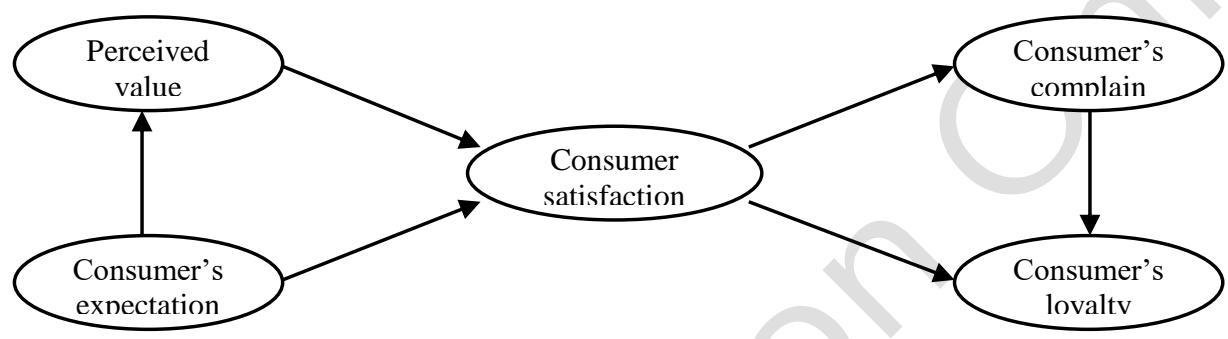

Figure 7. Sweden Consumer Satisfaction Index Model

In 1989, Sweden took the lead in developing the index model for consumer satisfaction on national level under the direction of Professor Fonell et al. of University of Michigan in American. This model has five structure variables: consumer's expectation, perceived value, consumer satisfaction, consumers complain and consumer's loyalty, as being shown in the figure, in which consumer's expectation is an exogenous variable, and others are endogenous variables.

\subsection{American Consumer Satisfaction Index Model (ACSI)}

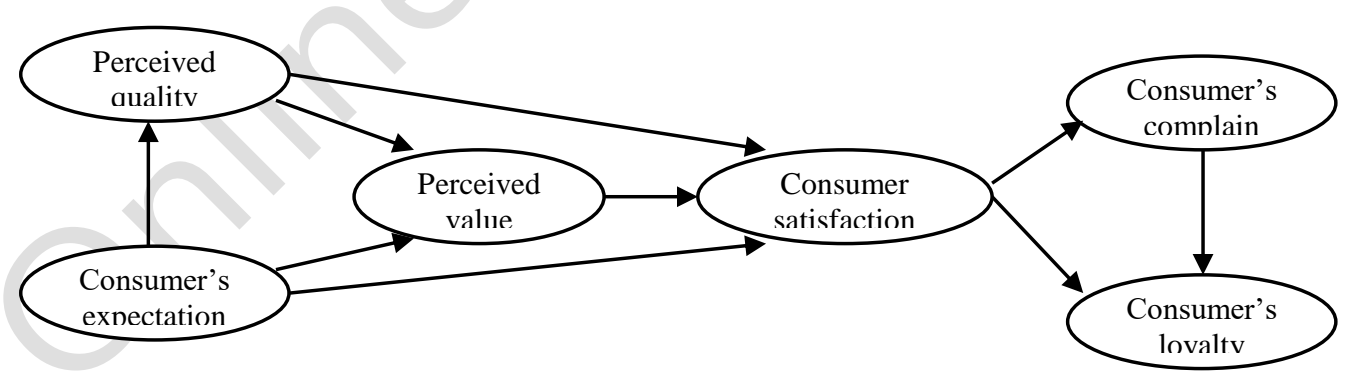

Figure 8. American Consumer Satisfaction Index Model

Fonell et al. established American Consumer Satisfaction Index Model (ACSI) on the base of SCSB model, in which a structure- perceived quality is added. In the six structure variables, only consumer's expectation is an exogenous variable, and others are all endogenous variables. These structure variables are operated through a series of observed variables, see [Table 1] for details. 
Table 1. Structure variables and observed variables in ACSI

\begin{tabular}{|c|c|}
\hline $\begin{array}{l}\text { Structure } \\
\text { variables }\end{array}$ & Observed variables \\
\hline $\begin{array}{l}\text { Consumer's } \\
\text { expectation }\end{array}$ & $\begin{array}{l}\text { 1. Overall expectation to quality; } 2 \text {. Expectation to product customerization; } 3 \text {. Prediction } \\
\text { to product reliability. }\end{array}$ \\
\hline $\begin{array}{l}\text { Perceived } \\
\text { quality }\end{array}$ & $\begin{array}{l}\text { 4. Overall evaluation to product quality; } 5 \text {. Evaluation to the quality of product } \\
\text { customerization; } 6 \text {. Evaluation to product reliability. }\end{array}$ \\
\hline $\begin{array}{l}\text { Perceived } \\
\text { value }\end{array}$ & $\begin{array}{l}\text { 7. Evaluation to the price under the given product quality; } 8 \text {. Evaluation to the product } \\
\text { quality under the given price. }\end{array}$ \\
\hline $\begin{array}{l}\text { Consumer } \\
\text { satisfaction }\end{array}$ & $\begin{array}{l}\text { 9. Overall satisfaction; } 10 \text {. Comparison of product quality with expectation; } 11 \text {. } \\
\text { Comparison of product quality with ideal product. }\end{array}$ \\
\hline $\begin{array}{l}\text { Consumer's } \\
\text { complain }\end{array}$ & 12. Complain times to manufacturer; 13 . Complain times to dealer. \\
\hline $\begin{array}{c}\text { Consumer's } \\
\text { loyalty }\end{array}$ & 14. Possibility of repeated purchase; 15 . Keeping the price. \\
\hline
\end{tabular}

\subsection{Europe Consumer Satisfaction Index Model (ECSI)}

Evaluation model of Europe Consumer Satisfaction Index (ECSI) was established by Gronholdt et al. on the base of American Consumer Satisfaction Index Model by adding image as structure variable, dividing perceived quality into two sections- perceived hardware quality and perceived software quality, and removing the structure variable of customer's complain, as being shown in [Figure 9]. In ECSI, for tangible products, perceived hardware quality is the quality of the product itself, and perceived software quality is service quality; for intangible products, perceived hardware quality is the quality of service attributes, and perceived software quality is some factors interacting with customers during service, including: language, behavior, attitude of service provider, environment of service place, etc. Structure variables and observed variables in ECSI are shown in [Table 2].

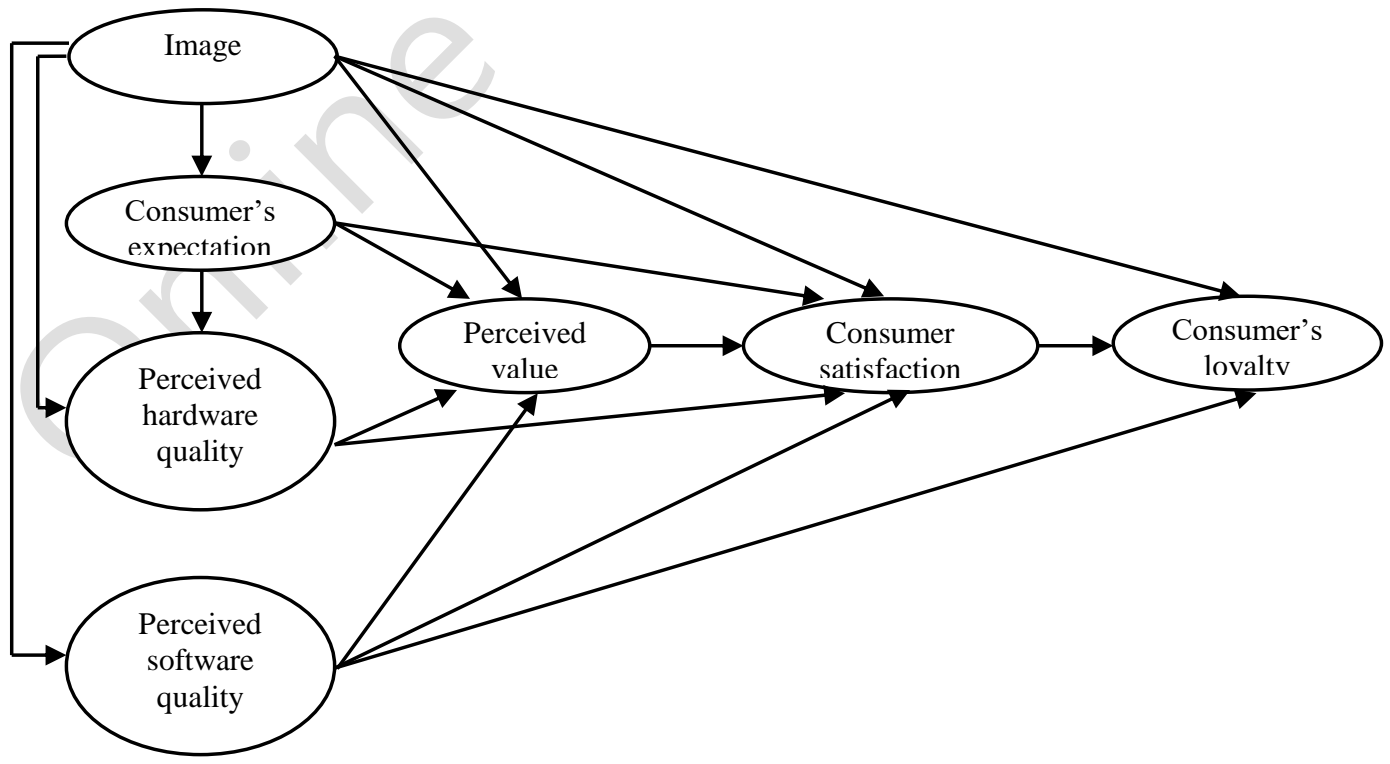

Figure 9. Europe Consumer Satisfaction Index Model (ECSI) 
Table 2. Structure variables and observed variables in ECSI

\begin{tabular}{|c|c|}
\hline Structure variables & Observed variables \\
\hline Image & 1. Overall image; 2. Operation practice; 3 . Enthusiasm; 4. Social responsibility. \\
\hline $\begin{array}{l}\text { Consumer's } \\
\text { expectation }\end{array}$ & 5. Overall expectation; 6 . Expectation to customerization; 7 . Prediction to reliability \\
\hline $\begin{array}{l}\text { Perceived hardware } \\
\text { quality }\end{array}$ & $\begin{array}{l}\text { 8. Overall evaluation to quality experience; } 9 \text {. Meeting the needs of consumers; } 10 . \\
\text { Comparing with competitors. }\end{array}$ \\
\hline $\begin{array}{l}\text { Perceived software } \\
\text { quality }\end{array}$ & $\begin{array}{l}\text { 11. Overall evaluation to quality experience; } 12 \text {. Meeting the needs of consumers; } 13 \text {. } \\
\text { Comparing with competitors. }\end{array}$ \\
\hline Perceived value & $\begin{array}{l}\text { 14. Evaluation to the price under the given product quality; } 15 \text {. Evaluation to the } \\
\text { product and service under the given price; } 16 \text {. Comparing with competitors. }\end{array}$ \\
\hline $\begin{array}{l}\text { Consumer } \\
\text { satisfaction }\end{array}$ & $\begin{array}{l}\text { 17. Overall satisfaction; 18. Comparison between the actual and the prospective; } 19 . \\
\text { Comparison between actual product and ideal product }\end{array}$ \\
\hline Consumer's loyalty & $\begin{array}{l}\text { 20. Possibility of repeated purchase; } 21 \text {. Possibility of purchasing other } \\
\text { products/services; } 22 \text {. Keeping the price; } \\
\text { 23. Possibility of recommending to friends }\end{array}$ \\
\hline
\end{tabular}

\section{Brief introduction to BP neural network and algorithm}

Since artificial neural networks appearing in 1940s, it has experienced a tortuous road consisting of three stages of rise, depression, and prosperity. Nonlinear characteristics, massive parallel-distributed structures and learning and generalization ability of artificial neural network enable its broad application in many respects such as modeling, time series analysis, pattern recognition, signal processing and control, etc. Especially for the knotty problems like shortage of physical or statistical understanding, statistical changes existing in the observed data, data being generated by a nonlinear mechanism, etc., neural network is able to provide a relative effective resolution.

Artificial neural networks (ANN) system appeared in 1940s. It is formed by connection of massive connecting weights of neural adjustable, has characteristics of massively parallel processing, distributed information storage, excellent self-organizing and self-learning ability, etc., being widely applied in the fields of information processing, pattern recognition, intelligent control and system modeling, etc. Especially the Error Back-propagation Training(BP network for short) may approximate any continuous function, having very powerful nonlinear mapping ability, moreover, parameters, such as number of the middle layer, number of processing units in the network and learning coefficient, etc. can be set according to specific circumstances with large flexibilities, therefore, it played an important role in many application fields. In order to solve the defects of slow convergence rate of BP neural network, convergence to the global point not being guaranteed, no theoretical direction to the selection of the middle layer of the network and its unit number, and the instability of network learning and memorizing, etc., many improved algorithms were put forward. BP network is able to learn and save a large amount of input- output mode mapping relation, and revelation and description of mathematical equation of this mapping relation are not required 
in advance. Its learning rule is to adopt the steepest descent method, continuously adjust the weights and thresholds of the network, enabling a minimum square sum of error. Topological structure of BP neural network model consists of input layer, hidden layer and output layer.

Evaluation model for customer satisfaction to B2C electronic commerce enterprises is established on the basis of BP neural network, BP network is able to realize any complex nonlinear mapping relation from input to output, and has excellent generalization capability, being able to complete the complex pattern recognition task. A typical structure of 3-layer BP network is shown in [Figure 10].

Learning process of the algorithm consists of forward propagation process and reverse propagation process. In the previous process, input information is processed layer by layer from input layer and via hidden units, and transferred to output layer, neural status of each layer only impacts neural status of next layer. In case of expected output not being obtained in output layer, it will shift to reverse propagation, error signal will be returned along previous connecting path, and minimized by modifying the neutral weights of each layer.

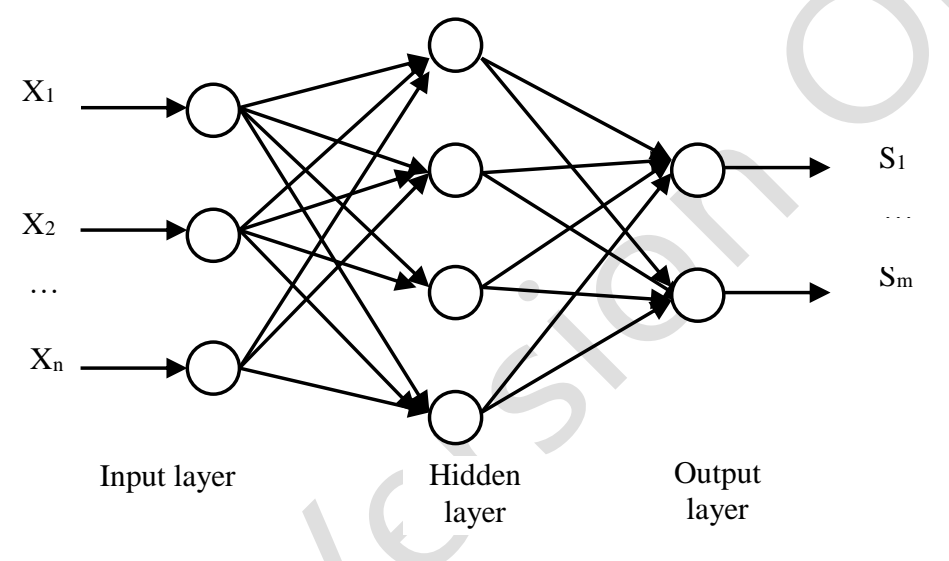

Figure 10. BP neural network structure of single hidden layer structure

Basic calculation procedure of the algorithm is as follows:

(1) Initialization. Provide network connecting structure according to actual issue (number of input variables and output variables), randomly set all connecting weights to arbitrarily small.

(2) Providing training sample. If input variable number is $\mathrm{n}$, and output variable number is $\mathrm{m}$, then form of each training sample is $\left(x_{1}, x_{2}, \ldots, x_{\mathrm{n}} ; t_{1}, t_{2}, \ldots, t_{\mathrm{m}}\right)$, where $t_{1}, t_{2}, \ldots, t_{\mathrm{m}}$ are the expected outputs as inputs being $x_{1}, x_{2}, \ldots, x_{\mathrm{n}}$.

(3) Calculating actual outputs. Calculate outputs of the nodes of each layer (excluding input layer) grade by grade by utilizing the nonlinear function $\delta_{j}=o_{j}\left(1-o_{j}\right) \sum_{k} \delta_{k} w_{j k}$, and
enable the final outputs to be $o_{1}, o_{2}, \ldots, o_{\mathrm{m}}$.

(4) Adjusting weights. Return to the node of hidden layer starting from the output nodes by recursive method, and continue to following formula to adjust the weights: $w i_{j}(n+1)=w i_{j}(n)+\eta_{o i} \delta_{j}$, in which oiis the output of No. I node of the upper layer.

If $\mathrm{j}$ is a node of output layer, then $\delta_{j}=o_{j}\left(1-o_{j}\right)\left(t_{j}-o_{j}\right)$; If $\mathrm{j}$ is a node of hidden layer, then $\delta_{j}=o_{j}\left(1-o_{j}\right) \sum_{k} \delta_{k} w_{j k}$, in which $k$ is all nodes of the
lower layer where node $j$ is located.

(5) Returning to step (2) and repeat the procedure till error e being satisfied. 
Customer satisfaction of electronic commerce and index of each satisfaction are classified into 5 grades, being very satisfied, satisfied, basically satisfied, dissatisfied, very dissatisfied, as shown in [Table 3].

Table 3. Customer satisfaction index of electronic commerce

\begin{tabular}{|c|c|c|c|c|c|}
\hline & $\begin{array}{c}\text { Very } \\
\text { satisfied }\end{array}$ & Satisfied & $\begin{array}{c}\text { Basically } \\
\text { satisfied }\end{array}$ & Dissatisfied & $\begin{array}{c}\text { Very } \\
\text { dissatisfied }\end{array}$ \\
\hline General satisfaction & 5 & 4 & 3 & 2 & 1 \\
\hline Product quality (A1) & 5 & 4 & 3 & 2 & 1 \\
\hline $\begin{array}{c}\text { Product } \\
\left.\text { performance( } \mathrm{A}_{2}\right)\end{array}$ & 5 & 4 & 3 & 2 & 1 \\
\hline Product price(A3) & 5 & 4 & 3 & 2 & 1 \\
\hline Service quality(B) & 5 & 4 & 3 & 2 & 1 \\
\hline $\begin{array}{c}\text { Distribution } \\
\text { efficiency(C) }\end{array}$ & 5 & 4 & 3 & 2 & 1 \\
\hline
\end{tabular}

Evaluation model constructed in this paper adopts the network structure of single hidden layer, and number of indexes is simultaneously taken as the node number of input layer, there are totally 5 nodes. And there are 3 primary nodes of hidden layer in this paper. Number of nodes of output layer is set to 5, i.e. output of 10000 indicates that result of satisfaction evaluation is "very satisfied", output of 01000 indicates that result of satisfaction evaluation is "satisfied", output of 00100 indicates that result of satisfaction evaluation is "basically satisfied", output of 00010 indicates that result of satisfaction evaluation is "dissatisfied", and output of 00001 indicates that result of satisfaction evaluation is "very dissatisfied".

According to above-mentioned index system, as per the learning sample, carry out normalized processing to each index value of customer survey of different electronic enterprises, and input the BP neural network established in accordance with above-mentioned structure. According to BP algorithm, determine weights calculation output between nerves of each layer. And carry out evaluation to customer satisfaction of electronic commerce as per evaluation standards according to the outputs.

After-sales evaluation data of 10 sellers in www.taobao.com are taken as the example in this paper, reorganize each index into basic data for training and inspection through normalization processing, as shown in Table 4. Carry out the training for weights in network by taking Seller 1, 2, 3, 4, 5, 7, 8, 9, 10 in it as training samples, and the weights and thresholds between input layer and hidden layer, hidden layer and output layer can be obtained. Error of this network is preset to 0.01 via initialization, after training reaching 1110 steps, error of network reached the set error requirement.

Table 4. Data Sheet of Samples

\begin{tabular}{|c|c|c|c|c|c|c|}
\hline & $\mathrm{A}_{1}$ & $\mathrm{~A}_{2}$ & $\mathrm{~A}_{3}$ & $\mathrm{~B}$ & $\mathrm{C}$ & Results \\
\hline Seller 1 & 0.919 & 0.902 & 0.923 & 0.974 & 0.951 & Very satisfied \\
\hline Seller 2 & 0.689 & 0.706 & 0.765 & 0.734 & 0.868 & Dissatisfied \\
\hline Seller 3 & 0.812 & 0.829 & 0.790 & 0.778 & 0.810 & Satisfied \\
\hline Seller 4 & 0.467 & 0.480 & 0.558 & 0.677 & 0.852 & Very dissatisfied \\
\hline Seller 5 & 0.890 & 0.875 & 0.846 & 0.840 & 0.896 & Basically satisfied \\
\hline
\end{tabular}




\begin{tabular}{|c|c|c|c|c|c|c|}
\hline Seller 6 & 0.703 & 0.712 & 0.709 & 0.753 & 0.850 & Dissatisfied \\
\hline Seller 7 & 0.945 & 0.950 & 0.921 & 0.908 & 0.932 & Very satisfied \\
\hline Seller 8 & 0.920 & 0.911 & 0.936 & 0.954 & 0.924 & Very satisfied \\
\hline Seller 9 & 0.789 & 0.790 & 0.807 & 0.810 & 0.805 & Satisfied \\
\hline Seller 10 & 0.690 & 0.689 & 0.656 & 0.879 & 0.712 & Dissatisfied \\
\hline
\end{tabular}

After network training is completed, taking Seller 1, 5, 9, 10 as the verification samples, input verification samples to verify the adaptability of the network, results of network output are shown in [Table 5].

Table 5. Results of network output

\begin{tabular}{|c|c|c|c|}
\hline Seller 1 & Seller 5 & Seller 9 & Seller 10 \\
\hline 0.9479 & 0.0632 & 0.0766 & 0.0054 \\
\hline 0.3345 & 0.8985 & -0.1556 & -0.1016 \\
\hline-0.3007 & 0.1365 & 0.9557 & 0.1659 \\
\hline 0.0367 & -0.0208 & 0.1345 & 0.9742 \\
\hline-0.0032 & 0.0045 & -0.0220 & 0.3542 \\
\hline
\end{tabular}

Comparison between network verified results and expected evaluation results, as shown in [Table 6].

Table 6. Verified results of network evaluation

\begin{tabular}{|c|c|c|}
\hline & Expected evaluation results & Network verified results \\
\hline Seller 1 & Very satisfied & Very satisfied \\
\hline Seller 5 & Basically satisfied & Basically satisfied \\
\hline Seller 9 & Satisfied & Satisfied \\
\hline Seller 10 & Dissatisfied & Dissatisfied \\
\hline
\end{tabular}

\section{Relationship between satisfaction and loyalty degree of electronic commerce customer}

Since Copeland first mentioned the concept of customer's loyalty, there have been more than 200 kinds of definitions for customer's loyalty. There are mainly three viewpoints in academic circle: behavior theory, attitude theory and combination theory of behavior and attitude. Customer's loyalty, in brief, is the behavior of customers to frequently and repeatedly purchase the product and service of the same enterprise (or brand). However, frequent and repeated purchase is not necessarily the real loyalty. If customer frequently visits mainly due to convenient purchase, attractive price, unclear information, etc., or has to visit due to high transfer cost, monopoly control, etc., once these factors disappearing, customers may be transferred. This kind of loyalty of customer is fictitious, and only brought a kind of temporary stability and prosperity to the enterprise, behind which crisis of different levels are hidden. Customer's loyalty degree is a measurement to customer's loyalty, and usually measured by indexes like surveying the visit times of customers to certain seller, purchase frequency to the product, purchase share, purchase intention and purchase preference, etc.

Loyalty degree of electronic commerce customer is defined as "consumers are more favorable to an e-commerce enterprise, which leads to repeated purchase behavior of consumers". Loyalty degree of electronic commerce customer studied in this paper refers to 
customer repeatedly and willingly overcoming obstacles and purchasing the product and service from certain seller, and willingly recommending this seller and its product and service to others.

There are many factors affecting the loyalty degree of electronic commerce customer, either on respects of enterprise, or on the respects of competitors, customers themselves, social environment. However, customer satisfaction is a decisive factor affecting customer's loyalty. Satisfaction experience for customer purchasing products has a significant impact on customer's repeated purchase behavior. Theory of customer satisfaction thinks that customer satisfaction will directly result in customer's loyalty, the higher customer satisfaction, the larger the purchase amount, and the more abiding the loyalty to the company and its brand; being deduced from traditional fields, satisfaction of electronic commerce customer will also have positive influence on customer's loyalty degree. Relationship model between satisfaction of electronic commerce customer and customer's loyalty degree is shown in [Figure 11].

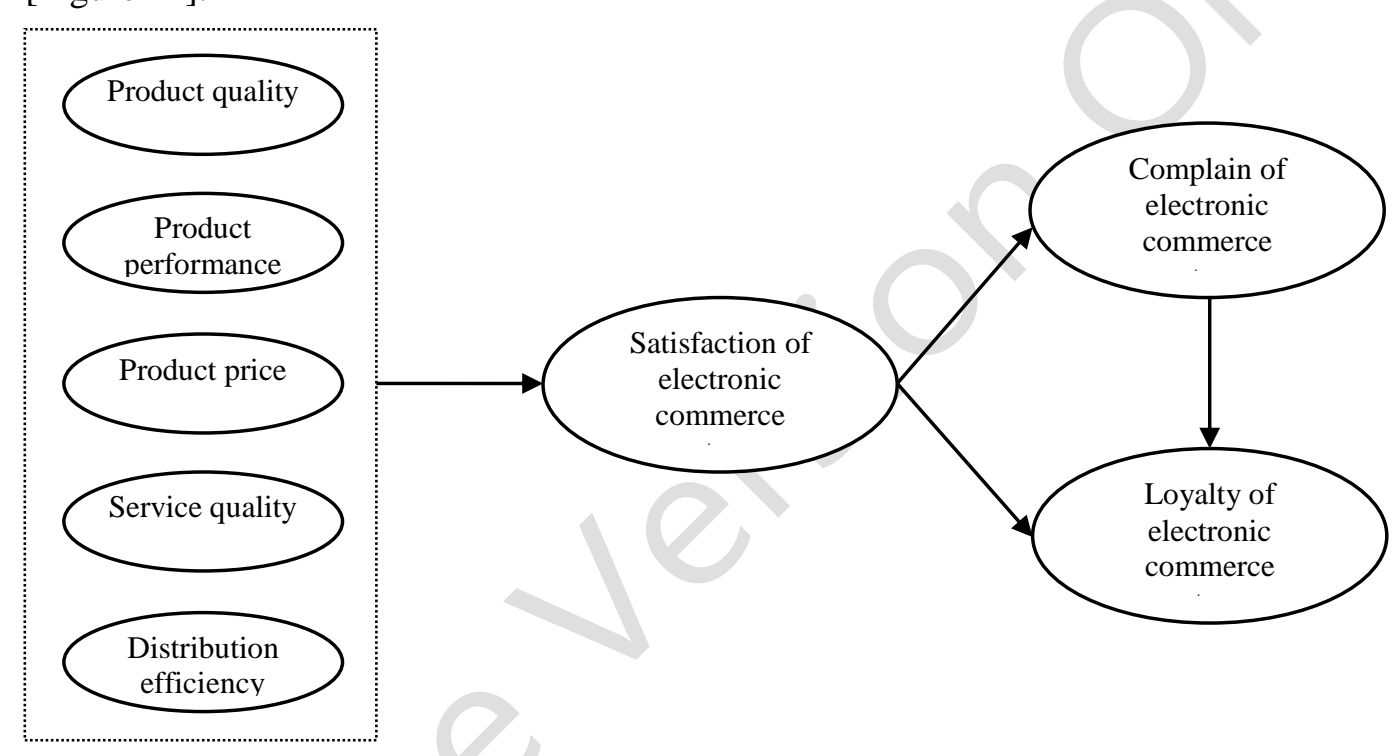

Figure 11. Relationship model between satisfaction of electronic commerce customer and customer's loyalty degree

In the environment of electronic commerce, one of the reasons for customer's loyalty is the willingness to keep mutual relationship due to the high satisfaction to the product. High quality is the foundation to form the loyalty of electronic commerce customer, reliable product quality, excellent product performance, suitable product price are the basic requirements to high quality product, customers can obtain high satisfaction only by high quality product, high service quality and high speed distribution efficiency, and customers can only form the desire of repeated purchase if they obtain satisfying product.

However, depending on different types of sold commodities, relations between customer's satisfaction degree and customer's loyalty in electronic commerce will be somewhat different.

(1) For most commodities, such as articles for daily use, clothing, etc., there is a certain degree of significant positive relationship existing between consumer's satisfaction degree and consumer's loyalty, and satisfaction is one of the important determinants to brand loyalty, consumers who are highly satisfied with the goods or services have high brand loyalty, and 
have the behavior of repeatedly purchasing the same brand. On the contrary, consumers who are unsatisfied with the goods or services have low brand loyalty, and have the behavior of brand switching. Consumer's loyalty is directly affected by consumer's satisfaction degree, there is positive correlation between them.

(2) For home appliances, automotive and other categories of goods, the relation between consumer's satisfaction degree and consumer's loyalty is asymmetric, most of the loyal customers are satisfied, but it cannot be predicted that satisfied customers are also loyal, although a higher quality can bring a higher satisfaction degree, a high satisfaction degree may not be able to directly convert to high consumer's loyalty. Empirical research indicates that $65 \%-85 \%$ of customers who are satisfied or very satisfied with the products have ever had the act of treachery, and in automobile industry, among $85 \%-95 \%$ of customers who are satisfied with the products, only $30 \%-40 \%$ have the act of re-patronage. These are also the specific description of non-positive correlation between consumer's satisfaction degree and consumer's loyalty.

Therefore, it is not all consumers who are satisfied with the goods or services will show loyalty for repeatedly purchasing the same goods or services. However, a high satisfaction degree cannot bring a high consumer's loyalty, but a low customer's satisfaction degree will bring negative effect on consumer's loyalty.

\section{Conclusion}

It can be seen from the results of verification and comparison that network evaluation results are basically the same as actual evaluation results. Implementation, training and verification were carried out for the created network model with network tool box in MATLAB software, verification results indicated that this model could obtain relative accurate evaluation results. This marked that the evaluation model for customer satisfaction to B2C electronic commerce had been successfully established on the basis of BP neural network, and the training of learning sample had been completed. As customer satisfaction of electronic commerce being evaluated later, evaluation data can be obtained just by inputting the standardized index data of evaluated sample.

\section{Acknowledgement}

This study was funded by the Scientific research project of Harbin University of Commerce (17XN058).

\section{References}

[1] Zhang Yanrong, and Wang Nihong, "Research on pests and diseases expert system of urban forst based on agent," Source:2010 International Conference on Computer Design and Applications, pp.173-176, (2010) DOI: 10.1109/ICCDA.2010.5541190

[2] Zhang Yanrong, and Wang Nihong, "Research on pests and diseases diagnosis expert system of urbanforst based on fuzzy reasoning," 2010international conference on computer design and applications," pp.425-428, (2010) DOI: 10.1109/ICAIE.2010.5641465

[3] Dengju Yao, Xiaojuan Zhan, "Design of sip-based centralized video conference system," 2012 IEEE International Conference on Cyber Technology in Automation, Control, and Intelligent Systems (CYBER), pp.246-249, (2012) DOI: 10.1109/CYBER.2012.6319933

[4] Wu Changwei, Lei Guohua, and Yang Ru, "Design of timber management system based on internet of things," Forestry Machinery \& Woodworking Equipment, vol.11, pp.42-45, (2012) 